\title{
Bento Prado Jr. entre Bergson e Wittgenstein
}

\author{
Bento Prado Jr. between Bergson and Wittgenstein
}

Antonio Ianni Segatto ${ }^{1}$

\section{Resumo}

Meu propósito neste texto é duplo: 1) pretendo mostrar que a leitura de Bergson e Wittgenstein feita por Bento Prado Jr. é motivada por uma mesma questão filosófica, a saber: qual é o destino da ilusão transcendental kantiana na filosofia contemporânea?; 2) retomando a comparação entre os dois autores sugerida por Bento, pretendo colocar duas perguntas: será que, sob a aparente proximidade entre Bergson e Wittgenstein no tratamento da questão mencionada, não se esconde uma divergência intransponível entre esses autores? Será que, seguindo o espírito da leitura e apropriação da filosofia wittgensteiniana por Bento, não seria necessário recusar o bergsonismo em nome da concepção terapêutica de filosofia de Wittgenstein? Pretendo mostrar que ambas as questões devem ser respondidas afirmativamente. Isso coloca um problema para a reflexão de Bento sobre a questão inicial, uma vez que faz com que a apropriação simultânea de Bergson e Wittgenstein pareça inconsistente.

Palavras-chave: Erro. Ilusão transcendental. Bergson. Wittgenstein. Terapia.

\begin{abstract}
My purpose in this text is twofold: 1) I intend to show that Bento Prado Jr.'s reading of Bergson and Wittgenstein is motivated by the same philosophical question, namely: what is the fate of the Kantian transcendental illusion in contemporary philosophy?; 2) By resuming the comparison between the two authors suggested by Bento, I want to ask two questions: under the apparent proximity between Bergson and Wittgenstein in the treatment of the above-mentioned question, isn't there is an insurmountable divergence between these authors? In the spirit of Bento's reading and appropriation of Wittgensteinian philosophy, would it not be necessary to refuse Bergsonism in the name of Wittgenstein's therapeutic conception of philosophy? I want to show that both questions must be answered in the affirmative. This poses a problem for Bento's reflection on the initial question, since it makes the simultaneous appropriation of Bergson and Wittgenstein seem inconsistent.
\end{abstract}

Keywords: Error. Transcendental Illusion. Bergson. Wittgenstein. Therapy.

\footnotetext{
${ }^{1}$ Universidade Estadual Paulista - Campus de Araraquara. E-mail: antonio.ianni@unesp.br
} 
A produção filosófica de Bento Prado Jr. foi marcada por um diálogo constante com Bergson e Wittgenstein. Com efeito, se a filosofia de Bergson foi objeto de sua tese de livre-docência Presença e campo transcendental - escrita em 1965 e publicada, vale lembrar, apenas em 1989 -, foi a filosofia de Wittgenstein assumiu papel preponderante nos textos publicados na última década de sua vida. A trajetória intelectual de Bento foi marcada, portanto, em uma ponta e outra pelos filósofos mencionados, traçando uma espécie de travessia do continente à ilha. Engana-se, porém, quem acha que se trata de uma trajetória linear. Cumpre lembrar que Wittgenstein já era mobilizado, juntamente com o filósofo francês, em "Por que rir da filosofia?", publicado em 1979, e que Bergson será retomado, ao lado do filósofo austríaco, na última década de sua trajetória, por ocasião da tradução da tese para o francês.

É evidente que a leitura e apropriação de outros autores (por exemplo, Sartre, Rousseau, Deleuze etc.) foi decisiva para a constituição de seu pensamento. Gostaria aqui, porém, de me restringir à leitura que ele faz dos autores mencionados e, mais especificamente, à aproximação que sugere entre ambos. Meu propósito, para dizê-lo sem rodeios, é duplo: 1) pretendo mostrar que a leitura de Bergson e Wittgenstein feita por Bento é motivada por uma mesma questão filosófica; 2) a partir disso, pretendo colocar duas questões: será que, sob a evidente proximidade entre Bergson e Wittgenstein, não se esconde uma divergência intransponível entre esses autores? Será que, seguindo o espírito da leitura e apropriação da filosofia wittgensteiniana por Bento, não seria necessário recusar o bergsonismo em nome da concepção terapêutica de filosofia de Wittgenstein?

Em um de seus últimos textos, Bento iniciava sua homenagem a Gérard Lebrun confessando o quanto sua produção era devedora de uma "pequena obraprima" de autoria do professor francês:

A triste notícia de sua morte surpreendeu-me no meio de um trabalho, quando tomava notas acerca de uma questão que me persegue já há algum tempo. Sob o golpe da emoção, retomei imediatamente os textos de Lebrun, descobrindo com uma injustificável surpresa - como a memória nos falha! - o quanto meus assuntos e problemas de então deviam ao ensino de meu amigo na rua Maria Antonia desde a longínqua década de 60. Foi nos livros sobre Kant e Hegel, ainda inéditos nessa época remota, 
que redescobri, no final do século, uma interrogação continuada que me tocara profundamente, sem que tivesse plena consciência de seu sentido ou de sua força, nas exposições que precederam sua publicação. Em textos recentes, eu havia examinado algumas instâncias da confusão "categorial" entre erro, sonho, ilusão, loucura, frequentes na filosofia contemporânea e que cabia corrigir (como deve ser corrigida a própria idéia de "erro categorial") por uma recuperação do valor crítico da história da filosofia na estratégia geral do pensamento. (...) Mas não me refiro apenas a esses dois grandes livros que são Kant et la fin de la métaphysique e La patience du concept. Minha grande surpresa foi descobrir um pequeno artigo traduzido e publicado por Rubens Rodrigues Torres Filho sob o título de "Do erro à alienação". Trata-se de uma pequena obra-prima, consagrada ao novo estatuto atribuído por Kant à idéia de "erro", a contrapelo de toda a tradição do pensamento clássico (PRADO JR., 2005, p. 278).

Embora Bento se refira a seus "textos recentes", isto é, àqueles publicados na última década de sua vida, e ressalte o fato de que ele próprio via neles uma retomada tardia de um fio da reflexão de Lebrun, não é exagerado dizer que sua própria reflexão desde a década de 1960 tenha sido marcada por um mesmo problema tratado pelo colega francês no texto e nos livros mencionados ${ }^{2}$. As referências expressas de Bento ao pequeno artigo "Do erro à alienação" se iniciam com um texto publicado na Folha de S. Paulo em 2000 (PRADO JR., 2000). No entanto, já em sua tese de livre-docência ele se refere a Kant e o fim da metafísica, ao qual teve acesso ainda na versão manuscrita. Nesse sentido, ainda que Bento tenha decidido dedicar a tese à obra de Bergson num esforço de "dégagement de Sartre"3, acredito que parte significativa de sua produção, desde esse marco inicial, pode ser lida como o enfrentamento de um mesmo problema colocado por Lebrun, problema este que serve de ponto de união das duas pontas de sua reflexão representadas por Bergson e Wittgenstein.

\footnotetext{
${ }^{2}$ Conforme o relato de Paulo Arantes, pode-se supor que Bento conhecia a "pequena obra-prima" de Lebrun ao menos desde meados da década de 1960: "Ainda era calouro [em 1965] quando Bento Prado Jr. me passou uma pasta contendo uma dezena ou mais de artigos inéditos de Gérard Lebrun, com uma recomendação expressa: leia, estude e procure imitar, pois é assim que se deve pensar e escrever" (ARANTES, 1994, p. 25).

3 Sobre isso, Bento disse certa vez em uma entrevista: "senti a necessidade de ser sartreano até o fim, e Sartre dizia que media a evidência de uma ideia pelo coeficiente de horror que ela lhe causava; quanto mais desagradável uma ideia, mais chances tem de ser verdadeira - penser contre soi. Penser contre soi era, no caso, penser contre Sartre. E quem era mais diferente do que ele? Bergson. Então fiz um esforço de dégagement de Sartre através do Bergson e, seguramente, mais tarde seria auxiliado pelo Merleau-Ponty, que estava redescobrindo Bergson" (NOBRE; REGO, 2000, p. 208).
} 
Como o próprio Bento assinala na passagem citada, o que o interessava na leitura de Lebrun era “novo estatuto atribuído por Kant à idéia de 'erro', a contrapelo de toda a tradição do pensamento clássico”. Afinal, como ressalta Lebrun, do Teeteto de Platão às Meditações de Descartes, nunca se levantou a suspeita de que o erro poderia resultar de alguma fonte positiva, de que ele poderia resultar de uma "ignorância em pleno coração do saber”. O Teeteto traçava uma linha divisória bem definida entre saber e não-saber, do que resultava, em princípio, a impossibilidade do erro: "é impossível que aquele que sabe algo não o saiba e que aquele que não o sabe o saiba" (188a). Se existissem, o erro e a falsidade deveriam resultar da confusão entre coisas que se sabem e coisas que se ignoram. No entanto, uma vez traçada aquela linha entre saber e não-saber, essa possibilidade estava imediatamente vedada. Deve-se notar, porém, que o Sofista apresenta uma saída para o impasse ao introduzir uma distinção entre constatar e julgar:

Se se consente em não restringir o logos à constatação de um "fato atômico", a uma nominação bruta de o que é - e sim fazê-lo surgir quando (e somente quando) eu atribuo a um sujeito o que ele é, então o erro volta a tornar-se compreensível (...) Com o logos predicativo, abre-se um espaço no qual os absurdos não são mais alucinações: com o benefício do jogo entre conteúdo representativo e julgamento, pode-se dizer, sem ser louco, aquilo que não se verifica (LEBRUN, 2001, p. 16).

A solução apresentada por Descartes ao problema do erro segue a via aberta por Platão. Com efeito, na $4^{\mathrm{a}}$ Meditação, o erro é concebido como o resultado da "desproporção entre a infinidade do livre arbítrio e a limitação do entendimento" (LEBRUN, 2001, p. 16). E algumas passagens de Kant parecem fazê-lo um partidário da concepção cartesiana. A certa altura da Lógica, lemos que o erro resulta "do nosso próprio pendor a julgar e a decidir até mesmo nas situações em que, por causa de nossa limitação, não estamos capacitados a julgar e a decidir” (Kant 1974c, p. 481). No entanto, Kant nota que o erro não se reduz a um mero desvio da percepção e a um juízo precipitado. Ele distingue dois tipos de erros: aquele que consiste em julgar prematuramente e aquele que resulta da não observância do coeficiente de indeterminação do conhecimento. O equívoco do pensamento clássico está em enxergar de maneira invertida a relação entre ambos: 
Em certo sentido, o primeiro é uma forma do segundo: se julgo prematuramente sobre a verdade das coisas, é por não ter criticado o testemunho dos meus sentidos e por ter julgado sem me perguntar se eu tinha o direito de fazê-lo. Mas esse erro por estouvamento, sempre invocado pelos clássicos, corre o risco de dissimular o princípio do erro em geral (...) Ele aparecerá, portanto, como uma simples ignorância do todo - o que, objetivamente, é certo, mas, subjetivamente, insuficiente, pois omite-se o movimento imperceptível em que esqueci de levar em conta minha ignorância possível (LEBRUN, 1993, p. 61).

Kant certamente não nega que o erro só existe no juízo. Isso não significa, porém, que ele compartilhe a explicação cartesiana. Nem os sentidos nem o entendimento, por si mesmos, erram: “A fonte de todo erro terá de ser procurada única e exclusivamente na influência despercebida da sensibilidade sobre o entendimento, ou, para falar mais exatamente, sobre o juízo" (KANT, 1974, p. 480). Em seguida, Kant precisa esse ponto: "Em certo sentido, pode-se certamente fazer do entendimento também o autor dos erros, a saber, na medida em que ele, por falta da necessária atenção para aquela influência da sensibilidade se deixa induzir pela aparência que daí se origina” (KANT, 1974, p. 481). Ao não levar em conta o coeficiente de indeterminação de nosso conhecimento, passamos, sem perceber, de uma aparência a um julgamento incorreto, tomamos as razões subjetivas para julgar como se julga por razões objetivas. Um bastão imerso na água nos parece quebrado, mas essa aparência não é em si mesma verdadeira ou falsa, já que é precisamente assim que o bastão nos aparece. O erro surge quando julgamos que o bastão está de fato quebrado, quando consideramos a modificação perceptiva como uma propriedade do objeto. Nunca podemos deixar de perceber o bastão como quebrado quando imerso na água, assim como não podemos deixar de perceber o mar como mais alto no horizonte, mas podemos evitar o erro, abstendo-nos de julgar ou tendo ciência da indeterminação do conhecimento. Daí a distinção entre o erro ou o engano corrigível e a ilusão inevitável.

Dado o caráter inevitável de certas ilusões, resta à crítica revelar que justamente tais ilusões são a fonte positiva do erro. O que os filósofos até então fizeram foi apenas refutar, um a um, os próprios erros. Se eles sequer suspeitavam que o erro resulta de uma "ignorância em pleno coração do saber", eles não poderiam obstruir a fonte desses erros, nem evitar que a aparência, empírica ou transcendental, continue a nos levar ao erro em outros casos (cf. KANT, 1974, p. 
483). Não à toa, a explicação clássica do erro, com algumas poucas exceções, não ia além de um certo "psicologismo". É nesse ponto que se revela a originalidade da compreensão kantiana do erro "depois de Kant, a filosofia não tem mais necessidade de uma explicação psicológica do mecanismo do erro, mas de uma crítica da sofística natural em todos os seus níveis (...) há uma falsidade inscrita no coração do conhecimento, que não é acidental" (LEBRUN, 2001, p. 23). Em um sentido, a falsidade não é acidental, pois as ilusões se instalam nas próprias condições transcendentais do conhecimento. Na medida em que tais ilusões estão inscritas na natureza mesma da razão, essa faculdade é a fonte positiva do erro. Em outro sentido, porém, a falsidade é acidental, pois, ainda que a ilusão transcendental seja necessária, o erro que pode resultar dela não o é. Nenhum erro é absolutamente inevitável, de modo que a falsidade é contornável e, portanto, acidental. A ignorância das metafísicas, uma ignorância da ignorância, isto é, uma ignorância do coeficiente de indeterminação do conhecimento, não significa a falsidade intrínseca de seus conceitos.

Bento iniciava sua leitura Bergson retomando justamente a interpretação de Lebrun. Ele lembrava que "a dialética transcendental não é obra puramente negativa na sua demolição das pretensões do dogmatismo" (PRADO JR., 1989, p. 31). E isso porque, segundo a formulação de Lebrun repetida por Bento, "é tão importante compreender a necessidade das metafísicas quanto a necessidade de seu fracasso" (LEBRUN, 1993, p. 93)4. Não é difícil perceber, pois, que Bergson retoma a seu modo o problema kantiano da inevitabilidade da ilusão e o novo estatuto da ideia de "erro", já que "o erro não é o fruto de uma subjetividade caprichosa: ele traduz uma vocação inata da inteligência" (PRADO JR., 1989, p. 31). Mas Bento se apressa em notar que a comparação com Kant encontra um limite:

Paradoxalmente, a ilusão é necessária não somente porque reflete uma insopitável tendência da subjetividade, como é o caso da ilusão transcendental de Kant, mas porque também passa a ter, em Bergson, o seu fundamentum in re (PRADO JR., 1989, p. 31).

A crítica das ilusões é feita sempre no horizonte de uma nova ontologia, que entende o ser como presença. Não por acaso, há sempre uma diferença entre a

${ }^{4}$ A passagem é citada expressamente em Presença e campo transcendental (PRADO JR., 1989, p. $31)$. 
crítica ao nível das consequências e a crítica ao nível dos princípios. As várias ilusões (a prioridade do Nada, da Desordem, do Imóvel, do Possível) são em geral feitas no nível das consequências conforme exige o ideal de precisão, uma vez que o método bergsoniano deve respeitar as próprias articulações do real. A ontologia da presença é tanto condição de possiblidade de uma descrição do real como contínua criação de novidade, isto é, como duração, quanto fundamento para desmascarar a ontologia que sustém a ideia de Nada e ilusão que dela resulta

Uma vez que a duração se revelou o campo em que se dissolvem as antinomias do pensamento tradicional, uma vez dado o fato, resta, através da crítica da ideia de Nada descobrir-lhe retrospectivamente o direito, mostrando a possibilidade de um monismo em que não há contradição entre o Absoluto e a ação livre e em que a duração se transforma na própria substância do real. (PRADO JR., 1989, p. 36)

A "miragem da ausência" surge da suposição de que o Nada precede o Ser, o que institui uma ontologia fundada na imobilidade: o ser é concebido aí como uma espécie de conquista sobre o Nada. A argumentação bergsonina visa precisamente inverter essa ontologia. Cumpre ler a passagem em que Bento desvenda o primeiro passo da crítica bergsoniana da ideia de Nada. Depois de operar uma série de eliminações (a eliminação do mundo exterior, a eliminação da temporalidade da consciência, a eliminação das sensações do corpo próprio), a imaginação é vítima de uma ilusão:

O advento do Nada imaginário a que se chega através da supressão
da consciência dá-se em espetáculo. Há alguém que assiste a essa
supressão total e que nos informa a respeito dela. O espetáculo
exige o seu espectador e aponta para ele: o desaparecimento do
mundo e da consciência é contemporâneo do nascimento de uma
nova consciência ou de uma consciência de segundo grau. A
imaginação termina por encontrar um obstáculo insuperável:
esperando constituir a imagem de um Nada absoluto, vê-se
obrigada a reconhecer que seu alcance vai apensa até o limite no
Nada parcial. Aprisionada no interior da Presença, não pode a
imaginação extravasar os seus limites (...) A imagem do Nada é
sempre imagem de um nada relativo: Nada-de-mundo ou Nada-
de-consciência. A lição do movimento perpétuo entre a imagem da
dissolução do mundo e a imagem da extinção da consciência é
justamente a da impossibilidade do Nada absoluto (PRADO JR.,
1989, p. 51-2).

Um dos sentidos do "eleatismo paradoxal" de Bergson, para retomar a expressão de Arnaud François (cf. FRANÇOIS, 2009), é o seguinte: quando 
falamos do Nada, "efetivamente nada pensamos, não pensamos ao falar do Nada (...) mais precisamente, pensar o Nada é uma forma equivocada e insuficiente em todo caso, oblíqua - de pensar o próprio Ser” (PRADO JR., 1989, p. 61).

Em "Por que rir da filosofia?”, Bento retomava uma passagem decisiva da segunda parte da introdução de $O$ pensamento e o movente a fim de sugerir uma aproximação entre Bergson e Wittgenstein. Os falsos problemas, incluindo a miragem da ausência, são remetidos por Bento a um abuso de autoridade do princípio de razão suficiente, já que ele supõe uma "espécie de paradoxal prioridade epistemológica e ontológica do nada sobre o ser e do possível sobre o real” (PRADO JR., 1985, p. 129). No caso de Bergson, o problema era a origem do ser. Quando nos perguntamos "Como é possível que algo exista - matéria, espírito, Deus?", parece necessário remontar a uma causa, a uma causa da causa e assim indefinidamente. Diante do abismo, resta à imaginação fechar os olhos:

Digo que esses problemas se vinculam ao que não é, muito mais do que àquilo que é. Nunca, com efeito, nos espantaríamos de que algo exista matéria, espírito, Deus - se não admitíssemos implicitamente que poderia não existir nada. Figuramo-nos, ou melhor, acreditamos nos figurar que o ser veio colmatar um vazio e que o nada preexistia ao ser: a realidade primordial - seja ela chamada de matéria, espírito ou Deus viria então se acrescentar ao nada, e isso é incompreensível” (BERGSON, 2006, p. 68).

No caso de Wittgenstein, tratava-se de uma espécie de "gramática" do thamázein. Bento citava uma passagem da "Conferência sobre ética", em que se lê o seguinte: "é um contrassenso dizer que me espanto com a existência do mundo, porque não posso imaginá-lo não existindo" (WITTGENSTEIN, 2014, p. 48). Elucidar porque se trata de um contrassenso exige retomar alguns pressupostos que sustentam essa leitura do Tractatus logico-philosophicus. O sentido da proposição define-se pela possibilidade de descrever as coisas tal como efetivamente são e tal como efetivamente não são, ou seja, pela possibilidade de que seja verdadeira ou de que seja falsa. No início de suas "Notas sobre lógica", Wittgenstein escrevia: "para entender uma proposição p não basta saber que p implica 'p é verdadeira', devemos também saber que $\sim$ p implica 'p é falsa'. Isso mostra a bipolaridade da proposição" (WITTGENSTEIN, 1984, p. 94). A noção de bipolaridade exprime justamente aquela possibilidade. Compreende-se, então, porque Wittgenstein diz que o significado da proposição é o que corresponde ou 
não à proposição, tornando-a verdadeira ou falsa; mas seu sentido independe da verdade ou falsidade efetivas. Entender a proposição significa saber o que deve corresponder a ela se for verdadeira e o que deve não corresponder a ela se for falsa. As chamadas proposições filosóficas não satisfazem essa condição de sentido, pois resultam de uma combinação ilegítima de sinais, que não chega a constituir um símbolo. Isso porque não foi conferido significado a um ou mais de seus elementos, porque ao menos uma de suas partes não realiza uma possibilidade sintática e, assim, o sinal proposicional não chega a simbolizar, não chega a estabelecer relações projetivas com um estado de coisas. Sequer há algo que possa ser reconhecido como uma proposição. As únicas proposições que se pode dizer, isto é, as únicas proposições com sentido dizem respeito à existência ou inexistência de estados de coisas contingentes. As proposições da lógica, embora sintaticamente bem construídas, não têm sentido, pois não representam nada e são, no final das contas, analíticas. As proposições filosóficas, por sua vez, estão além ou aquém, conforme a interpretação que se adote, da sintaxe lógica da linguagem. Disso resulta que toda proposição com sentido é sintética a posteriori e diz respeito única e exclusivamente ao que é contingente, ao que é o caso, mas poderia, em princípio, não ser.

A partir disso, seria possível traçar um paralelo entre a crítica lógica da filosofia proposta no Tractatus e a crítica kantiana da metafísica dogmática. O projeto filosófico do Tractatus pode ser aproximado do projeto kantiano: trata-se de recusar o acesso àquilo que está além dos limites do que pode ser conhecido, limites estes impostos pela própria natureza das faculdades subjetivas do conhecimento, no caso de Kant, e pela forma essencial da proposição, no caso de Wittgenstein. Estaria, pois, bloqueado o acesso aos objetos tradicionais de que trata a metafísica. Mas o paralelo com a crítica kantiana pode, então, ser estendido. Se Kant teve de suspender a razão para dar lugar à fé, se teve que bloquear o projeto metafísico no plano da razão teórica para recolocá-lo no plano da razão prática, Wittgenstein bloqueia o projeto metafísico no plano da lógica, mas recupera-o no plano do sentimento místico:

Ao delimitar o campo do dizível e do pensável, o filósofo aponta para o inefável como télos de sua empresa. É mais ou menos como na Crítica da razão pura, onde se coloca para além do cognoscível 
as ideias de Deus, alma e mundo que, no entanto, constituem o alvo último (embora inatingível pela metafísica) da Razão. Idem pra Wittgenstein. Um pouco como Kant que dizia: 'tive que limitar o conhecimento para dar lugar à fé'. Wittgenstein diria: "tive de delimitar o campo do dizível para dar lugar à ética, à arte e à religião, isto é, à vida" (PRADO JR. 2004, p. 126-7)5.

No Tractatus, a ilusão recebia o nome de contrassenso e ganhava um novo estatuto, na medida em que dizia respeito ao próprio método, pois para traçar os limites do dizível parecia necessário violar tais limites e dizer o que não pode ser dito. Curiosamente, Bento remete a passagem da "Conferência sobre ética" citada por ele à concepção tardia de filosofia como terapia. Ainda que por razões diferentes, Bergson e Wittgenstein teriam mostrado, mais ou menos na mesma época, que o nada absoluto é rigorosamente inconcebível. Ambos visariam a “ilusão filosófica como uma doença, propondo duas etiologias do páthos metafísico, seja no emperramento do jogo de linguagem, seja numa diminuição do impulso vital” (PRADO JR., 1985, p. 133).

Duas décadas mais tarde, Bento retomaria a comparação entre Bergson e Wittgenstein. A dimensão terapêutica do método wittgensteiniano confluiria com um dos vetores essenciais do bergsonismo:

Essa convergência na definição do télos e do estilo da filosofia
transparece de modo luminoso na maneira como ambos
enfrentam a "questão fundamental da filosofia", ou seja, a
pergunta: por que há o Ser e não o Nada? Os textos cruciais são a
"Conferência sobre a Ética" de Wittgenstein, de 1929, e "Le
Possible et le Réel" de Bergson, de 1930, (atenção às datas!). Para
Bergson essa pergunta "fundamental" remete a um falso problema,
que deriva de uma confusão entre os domínios da teoria e da
prática. A suposição da problematicidade do Ser pressupõe a
possibilidade de se representar o Nada absoluto, isto é, uma
impossibilidade lógico-psicológica, que nada mais exprime do que

5 Essa aproximação usual entre Wittgenstein e Kant é contestada pela chamada leitura resoluta. James Conant nota que as noções de limite que os dois filósofos têm em vista são distintas (Cf. CONANT, 1991, p. 171). Kant não pretende traçar os limites do pensamento em geral, mas do uso legítimo das categorias, isto é, ele não pretende traçar os limites do pensamento per se, mas do pensamento sobre objetos. Nessa medida, a ilusão transcendental, enquanto parte da lógica transcendental, diz respeito à impossibilidade de um conhecimento suprassensível e mantém, por isso, sua inteligibilidade. Lembre-se que, para Kant, os objetos das metafísicas especiais (Deus, alma e mundo enquanto totalidade) não podem conhecidos, mas podem, ainda assim, ser pensados. Wittgenstein, diferentemente, pretende traçar os limites do pensamento em geral. $\mathrm{O}$ contrassenso não é, portanto, inteligível, pois não é possível transgredir os limites do pensamento, isto é, os limites da lógica. Nessa medida, Wittgenstein não estaria limitando o que pode ser pensado e dito a fim permitir uma outra forma de acesso aos objetos das metafísicas especiais; ele estaria mostrando que tudo que está além dos limites da lógica é "simplesmente contrassenso". 
um déficit ao mesmo tempo teórico e vital. A busca do fundamento ou da certeza absolutos não é índice de rigor teórico, mas cegueira diante da impossibilidade da dúvida absoluta, doença da vontade. Wittgenstein, na sua conferência, desqualifica do mesmo modo a questão do fundamento do Ser: "Mas é um não-sentido dizer que me espanta a existência do mundo, pois não posso imaginar que ele não existe" (PRADO JR., 1985, p. 263-4).

Tanto para Bergson quanto para Wittgenstein, a filosofia seria uma atividade de análise conceitual, uma análise que combate "o descarrilhamento dos conceitos por um mau uso do entendimento ou da linguagem ou, ainda, por uma espécie de paralisia da imaginação teórica, que nos torna prisioneiros de imagens hipnóticas e enganadoras" (PRADO JR., 1985, p. 263). Essa análise dissolveria os falsos problemas da metafísica, restituindo-nos uma visão mais clara das coisas (visão sinóptica ou intuição) e uma vida mais saudável e limpa. Ora, era justamente nesse ponto que Bento retomava a interpretação Gordon Baker, para quem essa dimensão terapêutica da filosofia wittgensteiniana "não tem lugar na sofisticada tecnologia da moderna filosofia analítica”.

Negando a presença de um propósito positivo nas concepções de Wittgenstein, Baker pretende distanciá-lo do projeto de uma geografia lógica da linguagem, que os soi-disants wittgensteinianos pretendem imputar-lhe. Ao contrário, tratar-se-ia para o filósofo apenas de "dirigir-se a problemas filosóficos específicos de indivíduos específicos e lançar luz sobre confusões que esses indivíduos deveriam reconhecer como uma forma de enredamento em suas próprias regras" (BAKER, 2004, p. 68). Para cada confusão particular e para cada indivíduo particular que sofre de dessa confusão, propõe-se uma certa terapia; para cada questão particular, há um método específico. É isso o que ele teria em vista quando escreve que "problemas, não um problema, são dissolvidos (inquietações afastadas)" (WITTGENSTEIN, 2005, p. 316), ou que "não há um método da filosofia, há, antes, métodos, assim como diferentes terapias" (WITTGENSTEIN, 2001, §133). Nesse sentido, Baker sustenta que Wittgenstein não pretendia combater os 'ismos' (dualismo cartesiano, platonismo, etc.), mas pretendia apenas fazer com que certos indivíduos reconhecessem suas confusões filosóficas. É certo que ele se volta contra Agostinho, Platão, Frege, Russell, o autor do Tractatus, etc., mas isso apenas para mostrar que estes pensadores específicos estavam equivocados a respeito de questões específicas. Nesse ponto, o 
comentador lembra que Wittgenstein, em certo momento, comparou seu procedimento à psicanálise:

seu propósito era fazer cada paciente reconhecer as origens de suas confusões conceituais particulares (especialmente por meio do trabalho com analogias ou imagens de que não estaria consciente) e o reconhecimento do próprio paciente das regras na quais está enredado é uma precondição da correção do diagnóstico, bem como da efetividade da cura (BAKER, 2004, p. 68).

Em vários de seus últimos escritos, Baker aponta alguns desdobramentos dessa proximidade entre o que entende ser o procedimento wittgensteiniano e a psicanálise. Em primeiro lugar, ele nota que Wittgenstein associava os problemas filosóficos a uma gama de termos correlatos, que indicavam estados de confusão mental como "tormento”, “medo”, “inquietação”, “ânsia”, "prejuízo”, “superstição”, “ilusão”, etc. Dada essa origem das confusões, sua cura não significaria solucionar um enigma, mas apenas conduzir aquele que sofre a um estado de calma, de alívio. Wittgenstein estaria mais preocupado em introduzir "diferentes pontos de vista, por meio da exploração de possibilidades negligenciadas, de causar mudanças em nossos modos de ver as coisas, realmente levando a mudanças da mente e modificando a vontade (como nós queremos ver as coisas)” (BAKER, 2004, p. 68). A terapia não poderia, pois, ser a imposição de um outro ponto de vista. Ela dependeria do reconhecimento por parte do paciente de que seu ponto de vista é unilateral e de que suas confusões resultam do aprisionamento num único modo de ver as coisas. Seu critério de adequação é eliminar a confusão de alguém que não encontra seu caminho no domínio da gramática. A questão que se coloca, portanto, é a seguinte: não estaríamos aqui muito distantes da crítica das ilusões da inteligência em nome de uma ontologia da presença?

Embora nunca tenha desenvolvido a comparação entre Bergson e Wittgenstein de forma sistemática, ela sempre esteve no horizonte da reflexão de Bento. Em uma entrevista concedida em 2000, ele anunciava um projeto jamais realizado:

Pretendo escrever um ensaio que teria por título "Imagens Bergsonianas e Imagens Wittgensteinianas". Bergson utiliza metáforas e imagens de forma racionalista e crítica. Joga umas contra as outras para efetuar uma espécie de catarse do entendimento, que é muito parecida com a análise conceptual. Julgo que Bergson e Wittgenstein têm a mesma estratégia no que 
tange ao uso das metáforas e das imagens, a mesma concepção acerca dos limites da filosofia e da necessidade de dissolução dos falsos problemas filosóficos. (SCHWARTZ, 2003, p. 194)

Ainda que possa haver uma proximidade no uso das metáforas e das imagens por Bergson e Wittgenstein, não se pode negar que suas concepções de filosofia e método são muito distintas. Além disso, não se pode negar que a dissolução dos falsos problemas filosóficos é feita em nome de propósitos muito distintos. Se retomarmos o problema que motivava a comparação entre Bergson e Wittgenstein, veremos que o tratamento o problema do erro e da ilusão se faz em nome de objetivos divergentes. A miragem da ausência, segundo Bergson, estava baseada no pressuposto de que o Nada precede o Ser e implicava uma ontologia centrada na imobilidade, uma vez que "o ser que deve vencer o nada tem que ter determinadas características que remetem a uma espécie de positividade pura - a imobilidade, a eternidade, o Ser idêntico a si, tudo o que possa recuperar a 'corrupção' do nada, do menos de ser" (MORATO PINTO, 2007, p. 25). Ora, a essa miragem opõe-se a ontologia da Presença, sempre uma "presença (junto a si)", com diz Bento. Há, pois, um deslocamento da teoria do conhecimento centrada em um sujeito não situado, como o sujeito transcendental kantiano, para uma ontologia, um retorno à "imediação da Presença". Em Wittgenstein, a terapia filosófica não visa restituir uma certa metafísica. Trata-se precisamente do contrário, isto é, mostrar que toda metafísica significa o aprisionamento em uma imagem que nos mantém cativos. Em outras palavras, a crítica da metafísica tradicional não visa a restituição do direito de cidadania da verdadeira metafísica, mas a libertação de toda e qualquer concepção metafísica, inclusive daquela que Wittgenstein, ele próprio, havia suposto no Tractatus. Sob a aparente proximidade entre Bergson e Wittgenstein no que concerne ao problema kantiano da ilusão transcendental, esconde-se uma divergência intransponível entre esses ambos no que concerne ao propósito filosófico que motiva suas investigações filosóficas. Seguindo o espírito da leitura e apropriação da filosofia wittgensteiniana por Bento, seria, portanto, necessário recusar o bergsonismo em nome da concepção terapêutica de filosofia de Wittgenstein. Bento, porém, nunca deu esse passo. 
14 | Opinião Filosófica, V. 10, n. 2, 2019 - Brasil Filosófico e seus pensadores

\section{Referências}

ARANTES, Paulo Eduardo. Um departamento francês de ultramar: estudos sobre a formação da cultura filosófica uspiana (Uma experiência nos anos 1960). São Paulo: Editora Paz e Terra, 1994.

ARNAUD, François. Por que o real é "articulado"? O eleatismo paradoxal de Bergson". In: MORATO PINTO, Débora Cristina; MARQUES, Cilene Torres (Org.). Henri Bergson: crítica do negativo e pensamento em duração. São Paulo: Alameda Editorial, 2009, p. 35-53.

BAKER, Gordon. Wittgenstein's method: neglected aspects. Oxford: Blackwell Publishing, 2004.

BERGSON, Henri. O pensamento e o movente: ensaios e conferências. São Paulo: Martins Fontes, 2006.

CONANT, James. The search for logically alien thought: Descartes, Kant, Frege and the Tractatus. Philosophical Topics, vol. 20, nº 1, p. 115-180 1991.

KANT, Immanuel. Logik (Werkausgabe VI). Frankfurt-am-Main: Suhrkamp, 1974. LEBRUN, Gérard. Sobre Kant. São Paulo: Editora Iluminuras, 2001.

KANT, Immanuel. Kant e o fim da metafísica. São Paulo: Martins Fontes, 1993.

MORATO PINTO, Débora Cristina. Crítica do negativo e ontologia da presença: a interpretação de Bergson segundo Bento Prado Junior. O que nos faz pensar, vol. 22, p. 23-48, 2007.

NOBRE, Marcos; REGO, José Márcio. Conversas com filósofos brasileiros. São Paulo: Ed. 34, 2000.

PRADO JR., Bento. Gérard Lebrun e o devir da filosofia. Discurso, vol. 35, p. 277296, 2005.

PRADO JR., Bento. Erro, ilusão, loucura: ensaios. São Paulo: Ed. 34, 2004.

PRADO JR., Bento. Erro e alienação. Folha de São Paulo, São Paulo, 30 Jan. 2000. Caderno Mais!, p. 12-13.

PRADO JR., Bento. Presença e campo transcendental: consciência e negatividade na filosofia de Bergson. São Paulo: Editora da Universidade de São Paulo, 1989.

PRADO JR., Bento. Alguns ensaios: filosofia, literatura, psicanálise. São Paulo: Max Limonad, 1985.

SCHWARTZ, Adriano (Org.). Memórias do presente, volume 2: 100 entrevistas do "Mais!" (1992, 2002). São Paulo: Publifolha, 2003. 
WITTGENSTEIN, Ludwig. Lecture on ethics. Oxford: Wiley Blackwell, 2014.

WITTGENSTEIN, Ludwig. Philosophische Untersuchungen - kritisch-genetische Edition. Frankfurt-am-Main: Suhrkamp, 2001.

WITTGENSTEIN, Ludwig. The Big Typescript TS 213 - German-English Scholars' Edition (edited and translated by C. Grant Luckhardt and Maximilian A. E. Aue). Oxford: Blackwell Publishing, 2005.

WITTGENSTEIN, Ludwig. Notebooks 1914-1916. Chicago: The University of Chicago Press, 1984.

Recebido em: 15/10/2019.

Aprovado em: 27/11/2019. 